\title{
A new neolepadid cirripede from a Pleistocene cold seep, Krishna-Godavari Basin, offshore India
}

\author{
Andy S. Gale, Crispin T.S. Little, Joel E. Johnson, and Liviu Giosan \\ Acta Palaeontologica Polonica 65 (2), 2020: 351-362 doi:https://doi.org/10.4202/app.00705.2019
}

Valves of a thoracican cirripede belonging to a new species of the Neolepadidae, Ashinkailepas indica Gale sp. nov. are described from a Late Pleistocene cold seep (52.6 ka), cored in the Krishna-Godavari Basin, offshore from the eastern coast of India. This constitutes the first fossil record of the genus, and its first occurrence in the Indian Ocean. Other fossil records of the Neolepadidae (here elevated to full family status) are discussed, and it is concluded that only Stipilepas molerensis from the Eocene of Denmark, is correctly referred to the family. Cladistic analysis of the Neolepadidae supports a basal position for Ashinkailepas, as deduced independently from molecular studies, and the Lower Cretaceous brachylepadid genus Pedupycnolepas is identified as sister taxon to Neolepadidae. Neolepadids are not Mesozoic relics as claimed, preserved in association with the highly specialised environments of cold seeps and hydrothermal vents, but are rather an early Cenozoic offshoot from the clade which also gave rise to the sessile cirripedes.

Key words: Cirripedia, Thoracica, Neolepadidae, cold seep, Pleistocene, Indian Ocean.

Andy S. Gale [andy.gale@ port.ac.uk], School of Earth, Environmental and Geographical Sciences, University of Portsmouth, Burnaby Building, Burnaby Road, Portsmouth PO13QL, UK. Crispin T.S. Little [C.T.S.Little@ earth.leeds.ac.uk ], School of Earth and Environment, University of Leeds, Leeds LS2 9JT, UK. Joel E. Johnson [joel.johnson@unh.edu], Department of Earth Sciences, University of New Hampshire, Durham, NH 03824, USA. Liviu Giosan [1giosan@ whoi.edu], Geology \& Geophysics, Woods Hole Oceanographic Institution, Woods Hole, MA 02543, USA.

This is an open-access article distributed under the terms of the Creative Commons Attribution License (for details please see creativecommons.org), which permits unrestricted use, distribution, and reproduction in any medium, provided the original author and source are credited. 
FoF Full text $(842.7 \mathrm{kB})$ 